\title{
DISCURSO FLEXIVEL, AS CORTES E A AMEAÇA AS DEMOCRACIAS
}

Leão Pereira Neto ${ }^{1}$

\section{RESUMO}

Diante do enfraquecimento do discurso de conceitos claros e com limites fixos, o regime democrático sofre ataques internos, que abusam das próprias leis editadas para promover um enfraquecimento do Estado Democrático de Direito. Sociólogos, cientistas políticos, filósofos mostram que o rápido avanço da idade contemporânea causou uma flexibilização não somente das ciências como também dos conceitos morais, éticos e de justiça. Neste trabalho são apresentados alguns argumentos que comprovam essa flexibilização e seus efeitos para a sociedade e principalmente para a democracia como um todo.

Palavras-chave: Flexibilização - regime democrático - teoria sistêmica - sociologia ciência política - direito - neurociência - cortes constitucionais.

\section{FLEXIBLE SPEECH, SUPREME COURTS AND THE THREAT TO DEMOCRACIES}

\section{RESUME}

The weakness of the discourse of clear concepts and flexible scientific limits promotes an internal attack to democracy with abuse the laws issued to promote a weakening of the State of Rule of Law. Sociologists, political scientists, philosophers show that the rapid advance of the contemporary age has caused a relaxation not only of the sciences but also of the moral, ethical and justice concepts. In this work, some arguments are presented that prove this flexibility and its effects for society and mainly for democracy as a whole.

Keywords: Flexibilization - democratic regime - systemic theory - sociology - constitutional courts.

\section{INTRODUÇÃO}

O novo e remodelado direito constitucional é um guardião que cotidianamente pede mais socorro para ajudar na sua tarefa de salvaguardar a ordem jurídica, os valores pertinentes à justiça, à liberdade e à democracia. Em verdade, não se pode mais pensar unicamente em categorias ideológicas fechadas, tendo a evidência de um entendimento multidisciplinar para

\footnotetext{
1 Graduado em direito pela Faculdade Cathedral de Ensino Superior, advogado, pós graduado em direito constitucional pelo instituto IDP e em ordem jurídica e ministério público pelo Fundação Escola Superior do Ministério Público do Distrito Federal, mestrando do programa de mestrado e doutorado do UNICEUB, BrasiliaDF.
} 
lidar com as questões preocupantes de defesa da ordem democrática. Para entender os diversos ataques sofridos, seria necessário abrir questionamentos sobre os valores sociais.

Esses valores comunitários têm se perdido frente a intenção dos representantes máximos acumularem mais poderes. Devido a algumas mudanças em conceitos relativos à moral, justiça, ética, senso de dever com o bem público, temos diversos exemplos preocupantes de tentativa de quebra do regime democrático. As vezes promovidos por uma movimentação interna, outras por um reforço internacional. E, apesar de se imaginar que um reforço internacional seria de grande ajuda para impedir essa captura dos valores e instituições, a questão de momento e de interesses é de uma importância se considerar.

Alguns pontos preocupantes foram tratados durante o curso e outros são trazidos aqui em quatro tópicos. Sem questionar a qualidade da intervenção no que tange a força para impedir o movimento contrário ao regime democrático, no primeiro tópico deste trabalho apresenta-se algumas razões para entender que uma movimentação preventiva é melhor do que uma movimentação tardia, como o que normalmente ocorre quando o órgão internacional intervém dentro de uma democracia

Razões que foram estendidas para o segundo tópico onde se inserem algumas considerações de sociólogos como Zygmunt Bauman. Mais adiante, após uma contextualização, inicia o terceiro tópico com a apresentação de um ponto de vista sistêmico sobre a formação dos problemas democráticos que, sem dúvidas, apresentam uma interligação forte.

A partir desse ponto, é salutar voltar a atenção para dois direitos basilares do regime democrático, quais sejam a liberdade de expressão e o direito ao voto como mantenedores do jogo democrático e sua ligação com a verdade e a transparência. No último tópico do trabalho, a evolução de estudos científicos mostra como funcionam as estruturas de pensamento que formam a tomada de decisão, não só do juiz, mas também do homem em geral. Diante dessas novas "descobertas", o principal questionamento é se a corte ainda capaz de promover isso? Por uma questão de mandamento constitucional, o juiz não pode negar-se a proferir uma decisão, porém na tentativa de oferecer um apontamento para essa resposta o tópico tenta elucidar como as cortes têm oferecido proteção.

\section{AGINDO CONTRA A INTOLERÂNCIA SOCIAL: QUAL O MOMENTO ADEQUADO?}


A democracia está longe de ser um exemplo perfeito de como construir um país, não se sabe ao certo qual modelo de sistema governamental seria adequado para cada país, mas a pretensão sempre é a mesma: no fim, o que se pretende evitar é a volta ao estado de natureza ${ }^{2}$. Apesar de não ser perfeito, a democracia é o sistema mais implementado em todos os países do mundo, com suas variações. A república é somente uma destas e parece ser a que indica mais ambivalência.

Essa ambivalência é influenciada em grande parte pelo próprio modelo capitalista do mundo, que sempre se viu voltado para o consumo. Nesse enredo é possível afirmar que enquanto a democracia se vê voltada com o desejo de ter mais quanto o ponto de referência (se igualando aos que possuem mais bens que a pessoa); enquanto a república se volta para a disposição do sacrifício, proclamando o bem comum sobre os desejos particulares de acumulação de riqueza independente de qualquer coisa.

Nesses termos, o que sempre se procura construir é um sistema que fique no meio dos pensamentos, nem ao tanto de acúmulo de riqueza sob qualquer custo, nem a máxima supressão dos direitos particulares em prol da sociedade. Mesmo o puro pensamento teórico desse caminho é tênue e complexo. Quando se leva para a prática temos o adicional da própria natureza humana, que normalmente habita entre os extremos.

Se pudermos entender a contenção e educação dos desejos como um modo de praticar a ética e a virtude, talvez possamos concluir esse artigo concordando com outro filósofo, o italiano Norberto Bobbio, um dos mais importantes a refletir sobre a ética e a política na segunda metade do século 20. Para ele, o fundamento de uma boa república, mais até do que as boas leis, é a virtude dos cidadãos.

Para a promoção dessas virtudes seria necessário a promoção de políticas públicas voltadas para a educação, que tem se mostrado com poucos resultados ${ }^{3}$ diante de outros países

${ }^{2} \mathrm{O}$ grande problema do estado natural é a liberdade. Na leitura de O Leviatã, Hobbes trabalha a liberdade fazendo uma distinção entre esta e o poder. No capítulo 21 do Leviatã há dois tipos de impedimentos. O impedimento intrínseco (que retira o poder) e o impedimento externo (que retira a liberdade). Como no estado de natureza não se tem nenhum dos impedimentos, todos são livres para fazer o que bem entendem sem nenhuma proteção a se esperar contra aquela atitude. O conceito de moral, de educação, de reciprocidade é tão pessoal no estado natural que não se pode falar em sociedade.

${ }^{3}$ Segundo o PISA, o Brasil continua com pouco rendimento nas principais matérias básicas (leitura, matemática e ciências). Dentre os países sulamericanos que fazem o teste, o Brasil se encontra em terceiro lugar. A relatoria ainda aponta que quase metade dos jovens não conseguem extrair do texto a ideia principal. Uma péssima notícia se considerar além de tudo o modo com que as notícias são escritas e divulgadas. 
com a mesma classificação do Brasil. Seria necessário uma outra discussão que findaria fugindo aos propósitos deste trabalho.

Normalmente o inter criminis do fato qualificado pelo art. 155 do Código penal brasileiro envolve uma situação de oportunidade. Que quanto se materializa, não há indicação de reação, para que o meliante não saque uma arma ou ceife a vida da vítima. O momento de prevenção desse tipo penal envolve uma constante precaução e tomadas de atitudes preventivas. Assim é com a situação que nos preocupa no presente trabalho.

Para se evitar a captura da democracia pelas formas de intolerância social, pelo populismo ou qualquer outro movimento que volta à tona como o próprio parlamentarismo branco deve-se agir em momento antes do acontecimento. Mas a complexidade desse agir está na questão de interesse e visualização do que se está acontecendo ao redor, fora do individualismo que se criou e fortificou nesses anos.

Claro que essa intervenção depende muito do interesse político existente na manutenção do sistema democrático em determinado país. Se por um lado a história nos mostra que a intervenção drástica na política interna de uma país pode levar a construção de conflitos mundiais, a intervenção sutil também não produz nenhum efeito real desejado, e por vezes somente de aparência.

Mas se a intervenção externa é complexa, como considerar uma resposta vindo internamente do sistema fragilizado? Neste ponto é preciso estabelecer as hipóteses a serem trabalhadas.

Vamos imaginar que em uma país do sec. XIX, onde haja uma lei exótica. Suponhamos que o chefe da nação está diante de uma crise sem precedentes, havendo a necessidade de fazer isolamento social para ninguém cometa um dos crimes bíblicos, matar o próximo. Esse isolamento reduz a grande movimentação financeira, para superar isso, eis a lei exótica: todos os setores deverão destinar para o fundo nacional parte de seu orçamento, que será redirecionado para os mais necessitados. Mais ainda, ficam suspensas as cobranças de dívidas. Mais ainda, todos os novos criminosos, deverão ser conduzidos a prisão domiciliar.

Atente-se que para essa lei exótica, "quase" todos os poderes são afetados, mas nem todos. Em nenhum momento, nesse exemplo hipotético, houve corte de salários dos poderes institucionais, mas houve afetação do caixa tanto do executivo, quanto do legislativo. Continuando na suposição, essa casa legislativa é a de menor credibilidade dos últimos anos e mesmo assim é onde o chefe de nação tem grande apoio. 
Nenhuma instituição funciona bem sem os recursos financeiros necessários para manter um efetivo adequado a ameaça a ser combatida. Nesse cenário imaginado, temos um judiciário que teve de manter "novos" criminosos fora da cadeia, com recursos reduzidos para manter seu pleno funcionamento ${ }^{4}$. Um poder executivo que teve, na sua administração sacrificado estrategicamente alguns setores, mas não o central do chefe de governo e um legislativo com pouca credibilidade.

Segundo as ideias de Eric Posner (POSNER, 2018) se a população não tiver o básico de formação e de segurança, qualquer outra discussão e definição de direito democrático, até mesmo a questão da moral se torna algo trivial ou desnecessário. Uma degeneração dá democracia pela corrupção (e outros fatores) e esse repúdio ao governo gera a crise que precisa de movimento drástico para se concertar.

No embate tradicional entre os direitos individuais e os direitos e deveres do Estado perante a sociedade cabe transformar a pergunta antes limitada a defesa da constituição para quem deve ser o guardião da democracia quando o ataque é interno? Apesar do medo de alguns anos passados de uma democracia judicial ${ }^{5}$, os vários exemplos mundiais (Brasil, México, Venezuela, Hungria, Polônia, Estados Unidos, Rússia e etc.) mostram que a maior probabilidade de ataque interno ao sistema democrático é decorrente da união do poder executivo com o legislativo, quando não decorrente de um ataque isolado do próprio Executivo.

Diante dessa probabilidade, somado com um grande arcabouço normativo existente, tanto de uma legislação nacional, quanto pela normativa internacional e os diversos acordos políticos assumidos entre as nações, a questão a ser trabalhada é se as cortes podem proteger a democracia e se há algum momento adequado para ser feito, pois se a hipótese de

${ }^{4}$ No que se refere ao Brasil, através do Conselho Nacional de Justiça, que reuni informações de 90 órgãos do Poder Judiciário, apresenta aspectos relativos à estrutura judiciária. Em seu último relatório apresentado (Justiça em Números 2019) apesar da redução de 514 unidades, o território brasileiro conta com 14.877 unidades que geram uma despesa próxima dos 94 bilhões de reais.

${ }^{5}$ Não seria possível traçar uma crítica agressiva ou intensa a esse medo sob o ponto de vista de Rousseau e a ideia do contrato social. Acontece que no estudo da propriedade, capitalismo e desigualdade social, há em algum momento histórico uma transformação da ideia de compartilhamento social para o de propriedade individual. Essa ideia poderia ter sido combatida segundo Rousseau pelos mais fortes, preparados e intelectuais da nação, contudo, na obra, Discurso sobre a origem e os fundamentos da desigualdade entre os homens, podemos notar que provavelmente foram estes que começaram com o ideal de propriedade. Se historicamente os mais bem preparados foram os que começaram a essas mudanças de pensamento, de regime, pode-se afirmar, sob esse ponto de vista que a desconfiança dos juízes é racional e até justificada. 
melhor momento é o preventivo, exige-se então a superação da necessidade de provocação da corte.

\section{SITUAÇÃO DO MUNDO MODERNO: A FLEXIBILIZAÇÃO DE CONCEITOS}

Na história contemporânea ${ }^{6}$, é possível notar fortes modificações de valores morais, éticos, justos e até mesmo daquilo que é aceitável para determinada sociedade. Reflexo disso, sentido principalmente em estruturas mais sólidas como o direito é o uso das normas de uma maneira de subverter o sistema antes conhecido como provedor de um forte sistema democrático para instalação de um governo mais autoritário.

Revolução, populismo, golpe, autoritarismo; a denominação em si varia, assim como as características, mas para cada uma delas os estudiosos do direito tentam entender como esses golpes internos ao sistema democrático se caracterizam para que possam se prevenir contra eles. Mesmo estando em época de linguagem digital, onde temos os códigos binários e tudo na mais perfeita ordem para funcionar, a falta de uma adequação fixa em que se possa trabalhar com firmeza em métodos preventivos também se apresenta aos estudos.

Essa falta de enquadramento em modelos antes conhecidos é fonte de estudo de outras ciências sociais também. Há diversos sociólogos e filósofos que tentam explicar essa flexibilização dos conceitos, as aproximações entre os conceitos que antes eram tidos como claros. E não somente conceitos, como entidades: O Estado e o povo. Apesar de sempre se imaginar como um ideal, o movimento hodierno de aproximação entre os dois tem se caracterizado mais como uma aproximação do "leviatã" a porta do vizinho.

Hoje tudo acontece muito rápido, por isso, mesmo ao se falar em história moderna e contemporânea, a partir da leitura dos clássicos - em que temos um certo padrão de acontecimentos comparados com os atuais - aparentemente, há uma aproximação entre os períodos históricos. O avanço tecnológico e a mudança rápida de paradigmas deixam um sentimento saudoso de antigos testamentos de conduta social e política.

Ao mesmo tempo, se espera que não se siga esses testamentos pelo efeito que causaram e poucos saudosos consideram desses tempos a falta de transparência, onde tudo era menos evidente, principalmente os defeitos da época. Mas retornando à afirmação de

${ }^{6}$ Considerar aqui a divisão clássica dos períodos históricos, compreendidos a partir da invenção da escrita com a idade antiga, passando para a idade média, a moderna e por fim a contemporânea que tem seu início a partir da revolução francesa de 1789. 
aproximação do "leviatã"7 : quando da escrita do livro, o Estado não era tão próximo da população. Havia mais instituições, que pouco eram claras com relação a sua estrutura e seu funcionamento. Os Poderes, a polícia, a mídia, até mesmo a igreja; todos faziam parte de uma série de distanciamentos do Estado, de como ele deveria funcionar.

Sempre se esperou do Estado a devida proteção de retorno ao mundo natural. Mas com o passar do tempo, o conhecimento de como o Estado providencia a organização social passou a ser mais transparente - temos mais acesso à informação de como as coisas acontecem. Isso também revela mais fragilidades do sistema, maior corrupção, deturpação dos códigos de integridade que estavam no imaginário social. Todos envolvidos de uma certa forma sejam pela ação ou pela omissão.

Assim, o "leviatã" que antes representava somente a ameaça do Estado de retirar toda a liberdade ou de não proteger contra o estado natural de guerra, com o aumento da desconfiança, dos discursos de ódio, das polarizações, ele passou a ser mais próximo dos institutos basilares sociais. Nesse caminho, em um movimento circular de razão e efeito, me utilizando de uma expressão muito empregada pelo sociólogo Bauman ${ }^{8}$, todos os conceitos passaram a ser mais líquidos.

Isso não necessariamente apresenta somente lados negativos. Com a flexibilização de conceitos e até de barreiras temos também uma maior clareza de como as ciências, antes tidas como totalmente diversas, começam a interligar. Sociologia, Política, Ciência comportamental, Neurociência, Economia, todos essas apresentam hoje uma certa ligação com o direito que para este estudo, valendo a pena algumas citações.

O espaço pós-moderno temos a queda da máscara de ilusões ${ }^{9}$ dos formadores do Estado. Assim, seria preciso tratar de uma outra forma os conceitos clássicos como justiça e

${ }^{7}$ Essa expressão aqui está sendo usada com referência a obra de Thomas Hobbes, O leviatã, publicada na época de 1660. A filosofia hobbesiana considera o homem naturalmente medroso, necessitando do poder para se proteger. Mas nesse medo, apesar da saída do estado natural, ressurge de uma forma que o contrato social não é mais suficiente para eliminar a desconfiança e o medo do outro, por isso, para ele o ideal era a concentração de poder no soberano, para que ele mantenha a segurança ao mesmo tempo que uma distancia da sociedade e reduzir o medo e a desconfiança.

${ }^{8}$ Em suas várias obras, ele titularizou a expressão de conceitos líquidos, trabalhados como uma crítica sobre a sociedade atual e uma forma de degradação dos conceitos e valores.

${ }^{9}$ Apesar de ser uma expressão utilizada por Bauman, não é tão estranha aos estudiosos de Rawls e sua obra, Teoria da Justiça (1971) em que propõe a existência de um véu de ignorância no momento da formação do contrato social. Para ele, uma decisão justa poderia sair do encontro de pessoas que desconhecem a posição social que ocupam, passando então a discutir todos os aspectos sem preconceitos. Contudo, com a eliminação do véu, todos abrem uma desconfiança em que a discussão vira uma disputa de poder e obtenção de vantagens. 
moral, virtudes buscadas normalmente dentro do Poder Judiciário. Até mesmo pelo avanço das tecnologias de informação e comunicação, o dinamismo social e o sentido de urgência e inovação da vida política é mais proeminente que em outros períodos históricos.

Se a ética não é mais aquela capaz de ser definida por códigos, se o maior incentivo do novo código seja a promoção de maiores acordos ao invés de decisões (e aqui não há campo mais aberto do que a elaboração de acordo entre as partes), o uso da experiência de lidar com as pessoas de uma forma mais próxima possa ser usada para a prolação de acordos e decisões, mas de forma alguma essa nova dinâmica social aceitará por muito mais tempo o mesmo molde rígido do direito hodierno ${ }^{10}$.

Sem dúvida, o que prevalece hoje é a ideia do plural. Pluralismo político, pluralismo social, ciências antes isoladas agora tem que imaginar formas e acumular conhecimento para poder lidar com a interdisciplinaridade para solucionar os problemas atuais. Isso também vale para os conceitos antes extremamente familiares para o direito de justiça, moral e ética. No individualismo de séculos passados, os legisladores ao construírem os códigos morais e éticos, não tiveram sucesso em concebê-los com a necessária abertura conceitual para os tempos modernos.

Assim, o exercício da escolha do que é moral e ético a fazer começou a se perder. Nas palavras de Bauman: "Substitui o conhecimento, que se pode aprender, das regras, pelo eu moral constituído pela responsabilidade" (BAUMAN, 1997, p. 21). A partir do momento em que os direitos sociais começam a promover mais do que uma vida segura e confortável para a sociedade como um todo, cresce também o sentimento de liberdade de escolha.

Essa liberdade de escolha, chegada de maneira relativamente abrupta traz a responsabilidade, sem a devida preparação intelectual para a escolha entre as opções para o exercício do melhor juízo. Os grandes pensadores do renascentismo e do iluminismo não imaginavam que teriam um efeito contrário ao imaginado. Por ser caracterizada como um exercício ambíguo o anseio da sociedade passou a ser sobre figuras que poderiam apoiar a

${ }^{10}$ A ideia do juiz ter mais "experiência" de campo para decidir aparenta pertencer a outro tempo (idade moderna), mas do modo atual do sistema não é o mais adequado para se seguir. A necessidade de reformulação do sistema de formação dos pensadores do direito, ressaltada a alguns anos em diversas reportagens, junto com uma diversidade de cursos de graduação, também se extende agora ao próprio conhecimento do julgador. A rápida modificação social, a inclusão de uma nova visão dos princípios condutores do processo, digitalizações de procedimentos passam a ser obstáculos que necessitam de uma rápida superação para se acompanhar o ritmo das transformações que ocorrem, principalmente em época de crise econômica e pandemias. 
escolhas feitas ou até mesmo dizer qual escolha fazer. Isso dava destaque não só ao legislativo e demais poderes instituídos, mas também a instituições religiosas.

Por esse motivo, a quebra da confiança nessas instituições abalou e ainda causa grande alvoroço no meio social, já que as instituições que deviam ofertar alguma segurança já não são de confiança devido a escândalos de corrupção, abuso de poder. Paradoxalmente, o que temos é a maioria das pessoas escolhendo o próprio bem-estar em detrimento do bem-estar social (BAUMAN, 1997, p. 286). O que também contradiz a imagem de um welfare state.

Se a única maneira de construção da moral é por meio do convício social, o crescimento do direito penal e das medidas de responsabilização não induz a um bom prognóstico relativo ao reestabelecimento da confiança tanto nas instituições, quanto nas pessoas próximas, antes consideradas referenciais. Hoje, a desconfiança no Estado é tamanha que cresce com facilidade a ideia de que a verdade é normalmente o oposto ao que se está sendo pronunciado. Se não vale a confiança cega a uma pessoa, também não vale o extremo oposto que seria o crescimento do ódio contra todos.

Em uma pesquisa realizada por Müller e Schwarz ${ }^{11}$, pela universidade de Princeton foi possível detectar o uso de redes sociais para o crescimento tanto do sentimento de ódio quanto da polarização das pessoas durante a campanha eleitoral de Donald Trump. Sendo possível chegar à conclusão que as atitudes tomadas pelo então presidente nas mídias sociais levaria a um crescimento dos crimes de ódio e redução das sanções (MULLER e SCHWARZ, 2019).

Apesar de também admitirem que as redes sociais podem ter uma boa influência no mundo tecnológico, o fato mais comum nesses tempos é que a incerteza moral cresce para a população, a medida em que os líderes constroem a sua própria, pondo em risco o interesse público e a própria democracia. Hoje existe um "dilema tecnológico", em que para resolver um problema técnico de hoje, se cria uma tecnologia, um novo problema para solucionar outro.

Um grande detalhe que a modernização tecnológica trouxe, isso desde a revolução industrial, é a divisão. Divisão de trabalho, de ciências, de raciocínio e de pessoas. O grande reflexo hoje é que o líder eleito para uma representação não mais faz parte dos representantes, ele se eleva, cria a própria moral e age conforme ela, esquecendo que faz parte de um todo sistema.

11 MULLER, Karsten; SCHWARZ, Carlo. From hashtag to hate crime: twitter and anti-minority sentiment. Princeton University: venter for Public Poly and Finance. Out. 2009 
Os fins ultrapassam os meios e a única característica que importa é a tornar real uma pretensão. Assim, a democracia se torna alvo dela própria à medida em que líderes usam do próprio sistema interno para poder se manter em suas lideranças. Em sua mais recente tentativa de permanência no poder, Viktor Orban, se utilizando de uma ameaça, produziu um projeto de lei que se aprovado dará capacidade de se manter no poder por meio de decreto ${ }^{12}$.

Na modernidade da razão e dos cálculos matemáticos, o que cresce é a incerteza moral. As estatísticas não podem mais servir de algo além da antecipação de movimentos para reduzir os danos. Não se pode alegar a ignorância, também não se pode ignorar que o isolamento das ciências seja capaz de resolver os problemas modernos. As ideias de um futuro melhor passam na verdade pela sobrevivência além da crise de saúde (causadas pelo COVID-19). Seria uma sobrevivência dos conceitos "morais sociais" a fragmentação provocada pelo mundo tecnológico contemporâneo.

Com isso também seria possível imaginar uma redução da polarização que leva a reações mais extremas hoje em dia. É necessário esclarecer que a polarização não é outra coisa que não uma resposta afetiva ao grupo político oposto. Isso deriva não necessariamente da relação direta com o outro, mas também com relação as propagandas.

Toda essa importância de discussão deriva principalmente do fato de aproximação entre o direito e a política e o direito e a moral. Houve um crescimento da Teoria Moral como reação ao sistema político desastroso. Esse sistema se viu como um sucessor e eliminador da arbitrariedade moral, impondo um centro rígido de prescrições morais que se espalharam pelo sistema jurídico.

Compartilham desse entendimento autores como Kaufmman (Filosofia do direito), Dworkin (Justice for hedgehogs), Habermas (Between facts and norms: contribuitions to a discourse theory of law and democracy) e Alexy (The argument from injustice). Segundo o entendimento trazido por Oliveira, Cortes e Wykrota (OLIVEIRA, CÔRTES e WYKROTA, 2018), a racionalidade tem ligação com uma moral, a qual todas as pessoas podem concordar e o uso do discurso moral na verdade pode proporcionar soluções e alternativas com diversos defeitos sistêmicos resultantes.

\footnotetext{
${ }^{12}$ Para mais detalhes, pesquisar reportagem publicada no site human rights watch, em 23 de março de 2020: https://www.hrw.org/news/2020/03/23/hungarys-orban-uses-pandemic-seize-unlimited-power, acessado dia 30 de março de 2020, as 14:50.
} 
A emoção e a polarização são características presentes nos casos difíceis, tanto é que podemos perceber isso em análises de decisões do controle concentrado de constitucionalidade, como por exemplo a ADPF 54, em que temos citação a dimensão ética dos princípios, a leitura moral da constituição. Todos os indícios psicológicos e da neurociência moderna apontam para uma impossibilidade de separação radial entra a razão e a emoção especialmente na presença de dilemas morais ${ }^{13}$.

\section{PENSANDO EM DEMOCRACIA}

Se a fragmentação e a evolução das ciências já não são mais suficientes para a solução de problemas sociais, democráticos, derivados tanto de ataques internos quanto externos, o novo pensamento que surgir deverá vir da comunhão de ciências. O direito, que apareceu na lista do Brasil como uma das áreas cientificas que necessita de modificação, singelamente, ao longo dos anos e mais concentrado em carreiras de mestrado e doutorado, vem estudando a interligação com áreas como a política, sociologia, economia, neurociência.

Isso leva a reconsideração até mesmo de uso de expressões como separação de poderes. Apesar de a muito não se entender como uma separação de fato ainda há muito discussão sobre que tipo de restrições são permitidas em uma democracia estável, especialmente no que tange a competência de cada um dos poderes. Cada uma delas poderia resultar em diferentes produções específicas, contudo, este pequeno ensaio se limitará conjugação de dois pontos: o pensamento democrático, especialmente no que tange ao uso do direito de expressão (neste tópico) e mais à frente no que tange a limitação de competência do Poder Judiciário para discussão de temas políticos.

Cada um dos temas tentará ser o mais abrangente possível na comunhão de tipos de ciências estudadas, na tentativa de escapar do problema de fragmentação levantado no primeiro tópico. A par dessas premissas, a análise do uso do direito de expressão passará tanto por análise do direito e na medida do possível, pensamento da sociologia e da economia.

Isso porque, em uma visão de sistemas, a solução de um problema está interligada com a solução de outro. Podemos afirmar que o maior problema de hoje é a desconfiança nos

${ }^{13}$ Vários estudos atuais tanto no campo da psicologia quanto no campo dos debates morais estudam a análise de pensamento com variações do dilema do trem desgovernado e as reações as pequenas variações do mesmo. Revelam que os sistemas cognitivos são bipartidos e a formação da decisão passa primeiramente por uma intuição ( $g$ ut feeling) do que é moral e justo a se fazer e somente após essa impressão é que se busca razoes para justificar tal intuição. 
outros, nas instituições, nas intenções pronunciadas, isso porque a desconfiança sempre ocorre no ambiente de ignorância. Então, o primeiro problema ser resolvido seria o da educação. Se todos tem qualificação para emitir sua própria opinião sobre política e ainda identificar quando as atitudes tomadas realmente vão de acordo com as intenções pronunciadas, pode-se recomeçar a falar em confiança e avanço.

Contudo, diante da extensão populacional, é evidente que não temos um modo adequado de propiciar essa educação sem deixar alguns outros pontos essenciais em falha. A premissa de promoção da eficiência baseia-se que a pessoa está adequadamente alimentada, com abrigo, vestimenta e outras condições mínimas de vida. Então o primeiro problema a ser solucionando seria o da saúde e o da pobreza. Mas isso requer uma cooperação internacional, que não se tem confiança de que todos vão promover o devido esforço de maneira igualitária de acordo com suas capacidades. E assim, voltamos para o problema inicial de confiança.

Os regimes democráticos sempre se caracterizaram - principalmente - por liberdade: de escolha, de votos, de expressão. Mas essa liberdade não necessariamente se liga a verdade e não garante o direito de ofensa a outro. Na realidade, para uma liberdade pronunciada, a democracia oferece boas restrições tanto aos discursos (liberdade de expressão), quanto ao voto (modo de voto e maneiras de conseguir o voto). Pode-se cogitar em afirmar que a democracia na realidade é um regime que deixa aberto pelo menos duas opções de escolha, não necessariamente um regime de liberdades.

A limitação quanto a liberdade de expressão está ligada tanto a pronúncia da verdade, quanto ao direito de ofensa (o conflito com outros direitos fundamentais). Se trata aqui de um conflito lógico pronunciado em diversas obras, inclusive cinematográficas: o direito a ter uma opinião não deve ser confundido com o direto a expressar essa opinião. Essa regra tem suas nuances alteradas conforme o entendimento do que seria "politicamente correto".

Mas, essa limitação sem a exclusão total é algo extremamente complexo de se alcançar, ainda mais quando já há construção abusiva do uso dessa flexibilidade. A Índia une um forte compromisso constitucional à liberdade de expressão com uma rígida proibição de código eleitoral na busca de apoio eleitoral. No caso Prabhoo vs. Kunte ${ }^{14}$, a suprema corte da

${ }^{14}$ Dr. Ramesh Yeshwant Prabhoo vs Prabhakar Kashinath Kunte. A. I. R, 1996. SC. O candidato ganhador do pleito eleitoral (Dr. Prabhoo) utilizou-se de brechas na legislação eleitoral à época e realizou três discursos (entre novembro e dezembro de 1987) apelando por votos não por sua qualidade como representante unicamente, mas como candidato religioso perfeito para a comunidade Hindu, promovendo ao mesmo tempo um discurso de ódio contra aqueles que não seguiam a mesma opção religiosa. Em sua defesa alegou que o uso de 
Índia considerou que o simples uso da religião para obtenção de voto já era dano suficiente a ordem pública, sem demais necessidade de efetiva lesão para poder cancelar o pleito. $\mathrm{O}$ intuito é de evitar que a "falta de razão religiosa" possa ser usada para a perturbação da ordem democrática.

Do outro lado do mundo, quando a Suprema Corte norte americana se deparou com o caso Dennis vs. U.S ${ }^{15}$, tentou-se estabelecer testes de ameaça válida a ordem democrática. $\mathrm{O}$ caso em si já havia até então (1949) sido considerado o caso mais longo a ser decidido em uma corte federal. E como não havia provas clara o suficiente, houve um certo afrouxamento das decisões de condenação nas instâncias inferiores. Dennis reduziu a distinção entre o tipo de agitação política que poderia ser proibida e o tipo que poderia ser criminalizado.

Porém estabeleceu no ano de 1951 teste de confronto entre a gravidade do uso do discurso contra a probabilidade de o mesmo causar danos a ordem democrática. A depender do resultado, o direito de liberdade de discurso poderia ser cerceado. A estabilidade política dos EUA leva os americanos a subestimar a necessidade de proteger os processos democráticos, mesmo contra aqueles que se disfarçam de candidaturas democráticas.

O teste de perigo claro e atual captura apropriadamente o que está em jogo na proibição criminal de organizações cujos objetivos são fundamentalmente antitéticos à democracia e que estão sendo acusados, de fato, por conduta ilegal. Infelizmente, nessas circunstâncias, o foco no imediatismo da ameaça de atividade ilegal é insuficiente para refletir a gravidade da ameaça nesses tempos em que os contornos morais são mais flexíveis.

Mas, e o compromisso com a verdade? Em uma forte crítica ao modo como a mídia se comporta atualmente, o cientista político Giovanni Sartori (SARTORI, 2001) ressalta que a televisão informa pouco e mal. Muito disso devido a necessidade de comercialização do desastre, fora a compra de propagandas e manipulação de informação. O grande mercado midiático hoje, aproveitando dos avanços tecnológicos, procurou se especializar em

discurso religioso não estava perturbando a ordem publica e ainda não havia um apelo direto através do aspecto religioso. Todas alegações negadas; ao final foi condenado por práticas corruptas e teve que entregar o cargo conquistado.

15 Onze líderes do partido comunista defendiam a derrubada violenta do governo dos EUA. Em alegações de defesa os membros do partido que estavam solicitando reformas socialistas e a chegada ao poder por meio de práticas pacíficas. Alegaram ainda que sua condenação violava os direitos da Primeira Emenda à liberdade de expressão e que eles não serviam perigo claro e presente para a nação. A promotoria não tinha provas suficientes para afirmar que os teus tinham um plano específico para derrubada do governo, mas podiam afirmar que o partido normalmente defendia atos violentos contra governos de oposição ao seu pensamento. 
propagandas direcionadas, que são feitas tanto por meio televisivo quanto por meios digitais como computador e celulares.

Fora a questão da propaganda direcionada, o chamado microtargeting e seus efeitos que aumentam ainda mais a polarização, natural do ser humano, provoca, através de falsas informações um aumento do sentimento de ódio contra o próximo que não tem a mesma linha de pensamento. Usar métodos desonestos para subverter a preferência eleitoral do público não é novidade, desde tempos recordáveis (escritos e denúncias feitas ao longo dos séculos).

Escândalos de interferência na contagem de votos; corrupção nos órgãos de vigilância; manobras de controle de voto: controle de alocação de urnas e períodos de votação, cabresto, impedimento para determinados grupos de trabalhadores ou de pessoas específicas; segregação de eleitores mais maleáveis. Basicamente nunca faltou razão para que se desconfiasse de resultados eleitorais, principalmente quando este é apresentado com diferenças ínfimas.

Para Hal Berghel, essas práticas nunca foram as novidades, a única mudança significativa foi no uso das mídias digitais: "Micro-targeting on social media platforms lets a political campaign exploit the strongest emotions and play on the vincibilities and fears of the most easily manipulated among us" (BERGHEL, 2018, p. 85). Aliás, muitos estudiosos políticos como Baumann e até mesmo Carl Schmitt acreditam que o mal do século atual é o uso da tecnologia. Todos apontam para o que já foi ressaltado anteriormente: a fragmentação do pensamento.

As respostas sobre essa fragmentação e de como se pensar na democracia é uma tarefa de uma complexidade que não teria sucesso em poucas páginas, se não em um livro totalmente dedicado a isso. Mesmo que se imagine um apontamento para as ideias utilitaristas de Mill, em que a moral se vale de um peso maior para escapar da lógica da máxima felicidade (não necessariamente justa) de Bentham, no estado atual em que a construção moral se dá mais de caráter individual do que social, deixaria totalmente a cargo do chefe da nação (dotado do maior poder Estatal) a escolha do futuro do país, o que foge totalmente do conceito democrático.

A opção também por uma visão mais econômica em que toda a reestruturação do sistema é voltada para a máxima eficiência (e aqui temos diversos conceitos variados de como considerá-la) também poderia subverter a ordem do atual regime somente em uma aristocracia ou até mesmo monarquia se o resultado fosse maior riqueza. E, pelos exemplos mundiais, 
parece não ser possível que um país acumule riqueza o suficiente para atender a necessidade de todos os cidadãos.

É um exercício frustrante imaginar que a maior integração das ciências e de todas as formulação até agora imaginadas do sistema teriam a capacidade limitada de oferecer um grau a mais de proteção para o mesmo sistema que estamos vivendo, em que problemas de confiança, educação, condições básicas de vida e saúde impedem que haja tanto um crescimento da nação quanto uma reformulação para melhorar o sistema estatal.

\section{A CONSTRUÇÃO DA DECISÃO: A CORTE COMO DEFENSORA DA DEMOCRACIA?}

Solicitações de troca de regime, troca de governante, de representantes, pedido de garantias constitucionais a serem atendidas pelo Estado, abuso de direitos. Todos esses temas envolvem muito mais uma natureza política do que eminentemente jurídica. E por maior que seja a desconfiança institucional generalizada, é ao Poder Judiciário que se recorre. E este, obrigado a responder, cada vez mais lida com um sistema onde cada vez menos as regras estão definidas.

Seguindo a lógica da teoria dos sistemas de Niklas Luhmann, o direito não poupa esforço teórico para explicar o ambiente externo, nesse intuito, cada vez mais ele vai se tornando complexo para que o ambiente externo (e as outras ciências com que tem contato) se torna mais simples. Longe de se tratar de uma simples legitimação de atos e fatos, o esforço para se obter uma regra de decisão no meio em que aos fundamentos são generalizáveis geram e que custam cada vez mais capital político passa a envolver a neurociência, a economia, política, agronomia, medicina, entre outras (LUHMANN, 2016, p. 166).

A segurança referida é o contraponto da flexibilização dos conceitos e pensamentos morais. No caos, nos momentos de incerteza, a primeira coisa que se busca é um princípio organizador, aquilo que já temos uma definição, uma orientação inicial. Seja regras procedimentais, definição de competência, direitos e deveres básicos. Assim o sistema normativo (tanto do sistema de Common Law, quanto o da Civil Law) vira o ponto de apoio nesse "mundo líquido".

A questão do capital político é na verdade um reconhecimento dos próprios pares, de forma que o acúmulo dele proporciona tanto uma maior autonomia de atuação quanto argumento de validade, legitimidade e força das decisões tomadas. Quanto maior a 
universalidade desse reconhecimento, maior também será a difusão do argumento de validade. Esse capital pode ser tanto transferido, quanto convertido (MIGUEL, 2003, p. 121). O transferido seria o originário do próprio campo político em que temos os partidos e os candidatos. Já o convertido pode ser entendido como fruto de uma acumulação lenta e continua, algo que hoje podemos encontrar dentro até mesmo do Poder Judiciário.

São infindáveis exemplos em que as cortes são chamadas para, no exercício interpretativo do código raiz da nação, emitir a palavra sobre determinada conduta valorada. Mas diante da perda de capital político das outras instituições estatais, este passa a ser mais requisitado e virou o foco de atenção dos estudos e frequentemente de preocupação, diante da possibilidade de transformação do regime democrático em um juristocrático e de um aspecto social há dúvidas quanto a qualidade do regime ${ }^{16}$.

O que se vê no caso dos Países sul-americanos e alguns europeus como o caso da Hungria é que as cortes foram criadas para exercerem o papel central na transição para um governo democrático, agindo com o objetivo de ser uma mudança duradoura. No caso da Colômbia, na época da nova constituição, todas as instituições estatais foram reforçadas, junto com os direitos humanos e a segurança civil, mas nenhuma instituição recebeu tanto reforço quanto o judiciário

$\mathrm{Na}$ verdade, tudo depende da configuração de legitimidade da corte para proferir decisões em que envolva forte ponderação de custos e benefícios, análises econômicas e demais questões políticas. Essa legitimidade depende tanto dos outros atores quanto do capital político adquirido pela instituição judicial. Além disso, o direito precisa se reinventar, se tornar mais complexo para que se possa comunicar e entender os sistemas ao seu redor. Por isso, cada vez mais o direito está menos limitado ao formalismo legal e a simples prolação da norma.

O direito já está longe de se limitar a razão, sem emoção, vigente somente pelas normas e simples pronunciação na atividade judicante. Em sua obra, Uma teoria da Justiça,

${ }^{16}$ Não é de hoje que parte da população de todos os países apresentam desdenho quanto ao regime democrático, quase como se não se importasse o regime implementado pelo país, se outras condições de vida fossem atendidas ou garantidas. Surge então questionamentos se o desdenho político é por conta da ignorância ou por conta que o povo sabe que o real poder vem de outro lugar (uma grande empresa de mineração por exemplo). Seria a democracia a mais perfeita forma de controle conservador e autoritário do individuo? Em troca do direito ao voto e das redes sociais, hoje, um líder de nação tem mais informação individual de cada cidadão do seu pais do que a Gestapo ou a União Soviética sonhavam em ter. Ao se realizar uma comparação das obras publicadas hoje em regime democrático, com outras publicadas em plena ditadura ou monarquias cruéis, também é possível de se questionar se o mercado é mais duro na repressão da criatividade do que a censura antigamente? 
Rawls acredita que os sentimentos morais são elementos motivadores dos comportamentos humanos, dos quais o juiz, longe de ser um semideus ${ }^{17}$, não deixa de ser influenciado e até mesmo usa dos mesmos para decidir em alguns $\operatorname{casos}^{18}$.

Quando o Supremo Tribunal Federal se deparou com a ADPF 54, ação ajuizada pela Confederação Nacional dos Trabalhadores na Saúde (CNTS), com intuito de mudança de entendimento com relação a interrupção da gravidez de feto anencefálico, que até então era considerado como conduta tipificada nos arts. 124, 126 e 128, incisos I e II do Código penal, vemos em diversas passagens, a questão dos sentimentos foi amplamente abordada: ora os sentimentos dos próprios Ministros e da sociedade, ora os sentimentos da gestante, da família e do feto. E, ao fim do julgamento, a Corte reconheceu, em votos divergentes, a situação difícil em que se encontrava, e foi possível constatar que ela não se manteve apática às questões sentimentais.

Verificou-se que os Ministros se apegaram à sensibilidade, sem abandonar a razão, para decidir o caso, demonstrando que o discurso jurídico não é, e não pode ser construído como mera subsunção, com base apenas na ideia de incidência automática e infalível da norma jurídica. O próprio Ministro Cezar Peluso, apesar do voto divergente da maioria, enfatizou que a decisão de cada magistrado ultrapassa a frieza da norma e envolve a formação, a cultura, o modo de ver, o modo de ser de cada magistrado, de cada homem e de cada mulher, que está atrás de cada toga.

O tipo de dinâmica construída hoje leva em consideração principalmente a imparcialidade do juiz e a desarticulação do modelo ideal construído anteriormente: essa imparcialidade leva consigo a qualidade de pressuposto de validade do liame formado entre os fatos apresentados como verdade, a fundamentação e as provas produzidas em determinado caso, resultando na decisão. Por isso a fragilidade do sistema mediante a denúncia de corrupção ou perda da imparcialidade.

Isso levanta questões não somente na capacidade do judiciário, mas também no próprio campo político dentro dos Congressos. Assim como o discurso moral, a ideia de se

\footnotetext{
${ }^{17}$ Me refiro aqui, principalmente, ao uso da expressão de juiz Herculano, um ideal regulador a ser buscado nas obras de Dworkin.

${ }^{18}$ Ao mesmo tempo que a elaboração de uma lei depende de organização dos grupos sociais, lobistas, e da emoção do povo em um determinado tempo para ser aprovada sem resistência, a decisão sobre políticas públicas requer, muitas vezes de um longo pedido de vistas ou de uma outra forma de pausa procedimental para que essas emoções possam a colaborar tanto na análise do julgamento, quanto no momento de cumprimento da decisão judicial.
} 
discutir política por um método racional implica em afirmar que no processo decisório, primeiro se escolhe a decisão, depois se pensa em quais argumentos morais serão utilizados para sua justificação. A moralidade política, para se manter moral, deve se manter distante do pensamento estrutural racional.

O que a neurociência nos traz é que a decisão, primeiramente, seria determinada por aspectos biológicos (uma disputa de circuitos cerebrais pelo controle da ação humana) e, em seguida, apareceria à mente consciente como o produto de uma justificativa que parece livre e original, mas que apenas ratifica uma decisão já tomada. Destes aspectos todos, faz sentido afirmar que tanto a imparcialidade quanto a neutralidade também ganham novos modelos interpretativos.

Se a imparcialidade pode ser traduzida como uma "postura a ser adotada pelo juiz como condição de validade do processo e legitimidade da jurisdição concretamente exercida" (ABREU e COLARES, 2018, p. 673), a neutralidade, por seu turno, não seria uma postura, mas um atributo ou característica do próprio sujeito, que o qualificaria e distinguiria, e de que não se poderia destacar ou despir. E quando se remete a Kelsen - e até mesmo a Dworkin temos uma possível exclusão do elemento "humano" no Juiz (ISSACHAROFF, 2015, p. 259).

Diante dessas questões, qual a razão para acreditar que o Judiciário, terá força ou se mostra adequado (como instituição) para impedir a tomada de poder? O que fazem os juízes serem boas opções de pessoas para decidir sobre políticas públicas? Será que as cortes podem realmente defender a democracia? Claro que uma resposta definitiva não será possível de apresentar aqui, talvez haja mais pontos a serem observados no estudo entre diversas Cortes feita por Issacharoff (Fragile Democracies, 2015) do que neste pequeno trabalho.

Neste estudo em que houve a análise de diversos cenários democráticos fragilizados e a atuação das respectivas cortes, não foi possível se obter uma resposta conclusiva sobre como a corte deve enfrentar o conflito político. Apesar disso, uma das alternativas propostas fora o uso de acordos internacionais para evitar que a corte seja aquela a enfrentar sozinha o sistema político nacional.

Sob uma diferente perspectiva, o intuito aqui seria destacar outros fatores que interferem nessa atividade judicante de certa forma independente do cenário fragilizado do regime democrático. Me refiro aqui a estrutura de pensamento, mais especificamente as considerações trazidas por Daniel Kahneman (KAHNEMAN, 2012). 
Para oferecer uma compreensão mais profunda de julgamentos e escolhas Kahneman procurou reconhecer e compreender a estrutura de funcionamento da mente, baseado nas descobertas no campo da psicologia, trazendo o que seria a neurociência da moralidade. Esta nada mais é do que uma atualização da filosofia utilitarista que fora primeiramente apresentada por Jeremy Bentham (1748-1832) e John Stuart Mill (1806-1873). As primeiras apresentações tentavam solucionar os dilemas de justiça e moral com análise de benefícios econômicos ou escolha daquilo que proporcionava maior felicidade a longo prazo, respectivamente.

Para Kahneman (KAHNEMAN, 2012) temos dois sistemas de pensamento (um intuitivo e outro reflexivo) em que a escolha da forma de pensar pode determinar o sucesso ou o fracasso da decisão, em termos práticos. O primeiro sistema, intuitivo, monitora continuamente o que está acontecendo fora e dentro da mente e gera continuamente avaliações dos vários aspectos da situação sem intenção específica e com pouco ou nenhum esforço $^{19}$.

Esse sistema está mais presente nas corridas eleitorais, como assim afirma

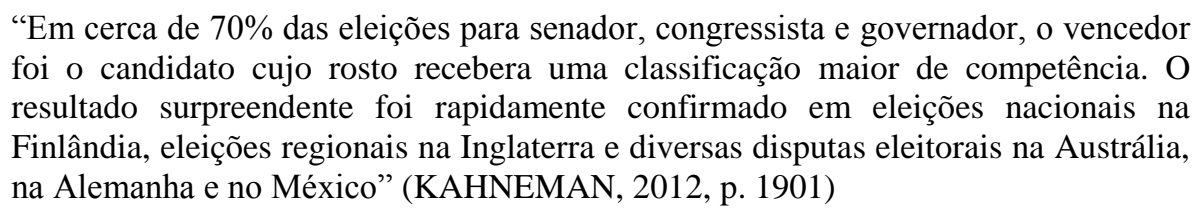

Já o segundo sistema é mais reflexivo, meticuloso, detalhista e lento. Este parece ser o mais adequado para a tomada de decisão, tanto no judiciário, quanto no próprio cenário de construção legislativa. O sistema 2 é responsável por gerar e receber perguntas e dirigir a atenção para a memória necessária para respondê-la. O problema é que o sistema reflexivo acaba racionalizando sobre os dados ofertados pelo sistema intuitivo (como ponto de ancoragem).

Essas descobertas têm impactos mais perceptíveis em questões sensíveis como tortura, perna de morte, em que há um contato pessoal mais direto. Mas também é perceptível em questões morais (principalmente nesses tempos contemporâneos) e em questões de vivência

\footnotetext{
${ }^{19}$ Ele é responsável por análises rápidas, automáticas, inconsciente e pouco precisas como fazer cara de aversão ao ver uma foto horrível, detectar hostilidade em uma voz, compreender sentenças simples e demais ações automáticas de pouco esforço mental
} 
em meio a quebra de normas e estruturas que permitem a manutenção do regime democrático (WOLKART, 2018).

Se para problemas mais complexos, o sistema reflexivo é o de uso preponderante, qualquer avanço interlocutório deve ser guiado por reflexões capazes de promover o maior bem-estar possível entre os envolvidos. Mas ao treinamento para evitar o uso do sistema intuitivo como ancora de pensamento precisa ser embasado por uma reformulação do entendimento de contraditório, ampla defesa e outras derivações do devido processo legal, que são de extrema importância por seu valor contributivo

Do ponto de vista sistêmica é impossível afirmar que as Cortes são capazes de proteger a democracia. Até mesmo porque ela depende de enormes recursos que são fornecidos e autorizados pelo Legislativo. Do ponto de vista processual, também não seria possível a boa coleta de informação para análise dos fatos e tomada de decisão se não houver participação de atores sociais e institucionais.

Diante disso é possível imaginar boas alternativas para essa defesa ${ }^{20}$, ainda que passível de críticas. Sejam elas voltadas a implementar mais mecanismos de controle para o Judiciário, seja voltada a reformulação do Legislativo, de melhoria do sistema de controle do Executivo. Porém, qualquer uma que se adote precisará passar tanto por uma releitura do entendimento do sistema jurídico e por uma “qualificação social”.

\section{APONTAMENTOS FINAIS}

Considerando as tendências anteriormente levantadas durante os tópicos, o gerenciamento da fragilidade do sistema democrático é possível, é possível afirmar que o reconhecimento das partes integrantes do Estado (ou do leviatã, segundo Rousseau), a perda de instituições formadoras de conceitos morais e protetoras da sociedade aumenta não só o descontentamento com o Estado e seus representantes, mas também faz com que os conceitos e os limites passam a ser mais flexibilizados, a corrupção somente pertence a outro que tem acesso ao poder e não a quem apontou o dedo.

Nesse "mundo líquido", a ideia do plural cresce em meio a flexibilização inclusive das normas de direito, que cada vez mais requisitam um maior exercício hermenêutico. E, cada

\footnotetext{
${ }^{20}$ Uma delas seria a utilização de instituições internacionais representativas, dos quais os países sejam signatários. Alternativa apresentada por Issacharoff.
} 
vez mais há necessidade de uma reestruturação da base de formação acadêmica e profissional, passando a ser evidente que o conhecimento de somente de uma ciência não é capaz de lidar com o ritmo de transformação social que se debate frente ao Estado. O direito, para lidar com a realidade social está mais complexo, e nessa complexidade sistêmica, começa também a estabelecer uma ligação mais clara com outras ciências.

Isso nos remete a um sentimento saudoso de tempos antigos, onde era mais simples de atuação e era possível solucionar as questões aqui levantadas com respostas positivas e negativas (mais um paradigma, já que a simples resposta negativa ou afirmativa se apresentam nos extremos de dois polos). Mas os tempos antigos também tinham seus defeitos, porém, de forma menos evidente.

Desde a formação do contrato social para o surgimento do Estado, a abertura da liberdade individual para o convívio em liberdade social é preciso. Dentro do regime democrático, tanto a liberdade de expressão quanto a pertencente ao campo político são as mais sensíveis de se alterar e aqui é possível trazer alguns casos sensíveis. É mais possível destacar que o uso dos meios digitais está sendo usado para aumento da polarização e manipulação de informações do que o contrário.

Porém, desde que seja feita uma transição de posição do uso da rede, podemos ter uma ajuda na proteção, além das instituições internacionais como sugerido por Issacharof em Fragile Democracies. Certamente, nesse ambiente virtual que só tem a crescer com o passar dos anos, uma reafirmação de preceitos morais, um compromisso com a transparência serve de movimento preventivo para prevenção de destruição da democracia.

Mas atualmente, o que ainda temos é um chamado para que as cortes, que ganharam reconhecimento como detentoras da última palavra quanto a interpretação dos mandamentos constitucionais, mesmo com a desconfiança da sua capacidade (que está cada vez mais perto do limite autorizado) e da sua integridade (quando estas se encontram capturadas ou estão sob influência de alinhamentos políticos, que na teoria não deveriam estar).

Aparenta essa requisição uma relação com o acúmulo de capital político ao longo dos anos, mas que a cada momento de intervenção força a perda, as vezes de forma exorbitante do capital acumulado. Fato é que a necessidade de provocação para a intervenção promove, ainda que não perceptível, uma atuação em um momento em que a violação já ganhou força. Isso por si pode ser mais desqualificador desse agente como mantenedor do sistema. 
Os avanços de outras ciências, e uma análise conjunta destas na tentativa de elucidar como as cortes têm oferecido proteção, tem mostrado que não só o sistema do direito é aberto, mas também o julgador que se envolve emocional e psicologicamente com o caso que está sob análise é um agente influenciável socialmente e politicamente.

Se há um medo de implementação de mais mecanismos de controle para o Judiciário, seja voltado a reformulação do Legislativo, seja para a melhoria do sistema de controle do Executivo, esse não seria o caminho a ser adotado. Ainda que passível de críticas, reforço que para a defesa da democracia, qualquer solução que visa uma atuação preventiva, seja envolvendo reformulação do sistema de ensino, seja pela via de uma melhor organização social (qualificando tanto a organização quanto seus participantes), parece ser de mais valia.

\section{OBRAS CITADAS}

ABREU, R. R.; COLARES, L. G. Fatores metaprocessuais e suas inflencias para a ofrmação da decisão judicial. Revista Brasileira de Políticas Públicas / Programa de Mestrado e Doutorado em Direito do UniCEUB., Brasília, agosto 2018. 662-688.

BAUMAN, Z. Ética pós-moderna. Tradução de João Rezenda Costa. São Paulo: Paulus, 1997.

BERGHEL, H. Malice Domestic: The Cambridge Analytica Dystopia. IEEE Computer Society, Los Alamitos, maio 2018. 84-89.

BOÉTIE, É. D. L. Discurso da Servidão Voluntária. $1^{\text {a }}$ Edição. ed. São paulo: Martin Claret, 2017.

CNJ. Justiça em Números 2018. Conselho Nacional de Justiça. Brasília, p. 214. 2018. (CDU 342.56).

ISSACHAROFF, S. Fragile Democracies. Cambridge: Cambridge University Press, 2015.

KAHNEMAN, D. Rápido e devagar: duas formas de pensar. Tradução de Cássio Arantes LEITE. eBook Kindle. ed. São Paulo: Objetiva, 2012.

LUHMANN, N. O direito da sociedade. Tradução de Saulo Krieger. São Paulo: Martins Fontes, 2016. ISBN ISBN 978-85-8063-298-9. 
LUNA, N. M. P. Pensar direiot e emoção: uma cartografia. Revista Brasileira de Políticas Públicas / Programa de Mestrado e Doutorado em Direito do UniCEUB, Brasília, agosto 2018. 28-48.

MARDEN, C.; WYKROTA, M. Neurodireito: o inicio, o fim e o meio. Revista Brasileira de Políticas Públicas / Programa de Mestrado e Doutorado em Direito do UniCEUB, Brasília, agosto 2018. 49-64.

MIGUEL, L. F. Capital político e carreira eleitoral: algumas variáveis na eleição para o congresso Brasileiro. Revista Sociologia e Política, Curitiba, junho 2003. 115-134.

MULLER, K.; SCHWARZ, C. From Hashtag to Hate Crime: Twitter and AntiMinority Sentiment. Princeton: Princeton University, 2019.

OLIVEIRA, A. M.; CÔRTES, P. D. R.; WYKROTA, L. M. Divergências de princípio: argumentos jurídios e morais em um cenário de desacordos sociais. Revista Brasileira de Políticas Públicas / Programa de Mestrado e Doutorado em Direito do UniCEUB, Brasília, agosto 2018. 89-115.

POSNER, E. A. The Trump Presidency: A constitutional Crissi in the United States? In: MARK A., G.; LEVINSON, S.; TUSHNET, M. Constitucional Democracy in Crisis? Oxford: Oxford University Press, 2018. p. 103-116.

ROUSSEAU, J.-J. Discurso sobre a origem e os fundametnos da desigualdade entre os homens. $1^{\text {a }}$ Edição. ed. Porto Alegre: L\&PM Pocket, 2008.

SARTORI, G. Homo Videns: televisão e pós-pensamento. São Paulo: EDUSC, 2001. ISBN 85-7460-059-8.

WOLKART, E. N. A neurociência da moralidade na tomada de decisoes jurídicas complexas e no desenho de políticas públicas. Revista Brasileira de Políticas Públicas / Programa de Mestrado e Doutorado em Direito do UniCEUB., Brasília, agosto 2018. 492522. 